\title{
Advanced Stirling Radioisotope Generator EU2 Anomaly Investigation
}

\author{
Edward J. Lewandowski ${ }^{1}$ \\ NASA Glenn Research Center, Cleveland, OH 44135 \\ Michael W. Dobbs ${ }^{2}$ \\ Vantage Partners, LLC, Brook Park, OH 44142 \\ and \\ Salvatore M. Oriti ${ }^{3}$ \\ NASA Glenn Research Center, Cleveland, OH 44135
}

\begin{abstract}
The Advanced Stirling Radioisotope Generator (ASRG) Engineering Unit 2 (EU2) is the highest fidelity electrically-heated Stirling radioisotope generator built to date. NASA Glenn Research Center (GRC) completed the assembly of the ASRG EU2 in September, 2014 using hardware from the now cancelled ASRG flight development project. The ASRG EU2 integrated the first pair of Sunpower's ASC-E3 Stirling convertors (ASC-E3 \#1 and \#2) in an aluminum generator housing with Lockheed Martin's Engineering Development Unit (EDU) 4 controller. After just 179 hours of EU2 generator operation, the first power fluctuation occurred on ASC-E3 \#1. The first power fluctuation occurred 175 hours later on ASC-E3 \#2. Over time, the power fluctuations became more frequent on both convertors and larger in magnitude. Eventually the EU2 was shut down in January, 2015. An anomaly investigation was chartered to determine root cause of the power fluctuations and other anomalous observations. A team with members from GRC, Sunpower, and Lockheed Martin conducted a thorough investigation of the EU2 anomalies. Findings from the EU2 disassembly identified proximate causes of the anomalous observations. Discussion of the team's assessment of the primary possible failure theories, root cause, and conclusions is provided. Recommendations are made for future Stirling generator development to address the findings from the anomaly investigation. Additional findings from the investigation are also discussed.
\end{abstract}

\section{Introduction}

$\mathrm{T}$ HE Advanced Stirling Radioisotope Generator (ASRG) Engineering Unit 2 (EU2) is the highest fidelity electrically-heated Stirling radioisotope generator built to date. NASA Glenn Research Center (GRC) completed the assembly of the ASRG EU2 in September, 2014 using hardware from the now cancelled ASRG flight development project. The ASRG EU2 integrated the first pair of Sunpower's ASC-E3 Stirling convertors (ASC-E3 $\# 1$ and \#2) in an aluminum generator housing with Lockheed Martin's (LM's) Engineering Development Unit (EDU) 4 ASC controller unit (ACU). ${ }^{1}$

The ASRG EU2 successfully completed characterization testing in November and December, 2014. The test results were as expected, and the generator demonstrated it would achieve over $28.6 \%$ efficiency (DC output power / gross heat input) in a deep space vacuum environment with a $4 \mathrm{~K}$ sink temperature. ${ }^{2}$

However, power fluctuations started to occur on both convertors shortly after EU2 testing began and after the convertors had operated for over 3,400 hours. Over time, the power fluctuations became more frequent on both

\footnotetext{
${ }^{1}$ Project Lead Engineer, Thermal Energy Conversion Branch, 21000 Brookpark Rd., AIAA Senior Member.

${ }^{2}$ Lead System Engineer, 3000 Aerospace Parkway

${ }^{3}$ Mechanical Engineer, Thermal Energy Conversion Branch, 21000 Brookpark Rd.
} 
convertors and larger in magnitude, up to $9.4 \mathrm{~W}$. Early power fluctuations were less than 2 seconds in duration, while later drops in power lasted for hours. Eventually the EU2 was shut down in January, 2015.

Given the flight-like fidelity of the EU2 hardware, with the ASC-E3 convertors and the EDU 4 controller, and the flight-like rigor that had been used to assemble the generator housing assembly (GHA), such an early failure was both unexpected and disconcerting. The EU2 was intended to be part of a broader program to establish a reliability database for future Stirling-based power systems, ${ }^{3}$ but this failure was a setback to that initiative. An anomaly investigation was chartered to determine root cause of the power fluctuations, to the extent possible, so as to learn from this event and then apply insights gained to future dynamic power conversion systems. The EU2 anomaly investigation team included members from GRC, Sunpower, and LM. Various GRC technology experts were brought in as needed to support different phases of the investigation.

This paper chronicles the EU2 anomaly investigation process that took place in 2015. Findings from the disassembly and inspection of the GHA and ASC-E3 convertors are discussed, along with the proximate cause of the power fluctuations. Extensive analysis, modeling, and follow-on testing was conducted, leading to possible failure theories and an assessment of likely root cause and conclusions. Recommendations are provided for future Stirling generator development.

\section{A. The ASRG EU2}

This section provides the reader with a brief description of the ASRG flight design generator, which was the basis for the ASRG EU2. Figure 1 shows a diagram of the ASRG flight unit, as designed by LM under contract to the Department of Energy. The ASRG contains two Advanced Stirling Convertors (ASCs) secured to one another with an interconnect tube. A General Purpose Heat Source (GPHS) module is held against each ASC heat collector to provide the heat input. The cold-side adapter flanges (CSAFs) conduct waste heat rejected from the convertors to the beryllium housing and fins, for radiation in a vacuum environment or convection to air. During ground operations argon fills the housing, sealed by o-rings and gaskets. A gas management valve allows access to the argon. A pressure relief device is provided to vent the argon during launch as the surrounding air pressure

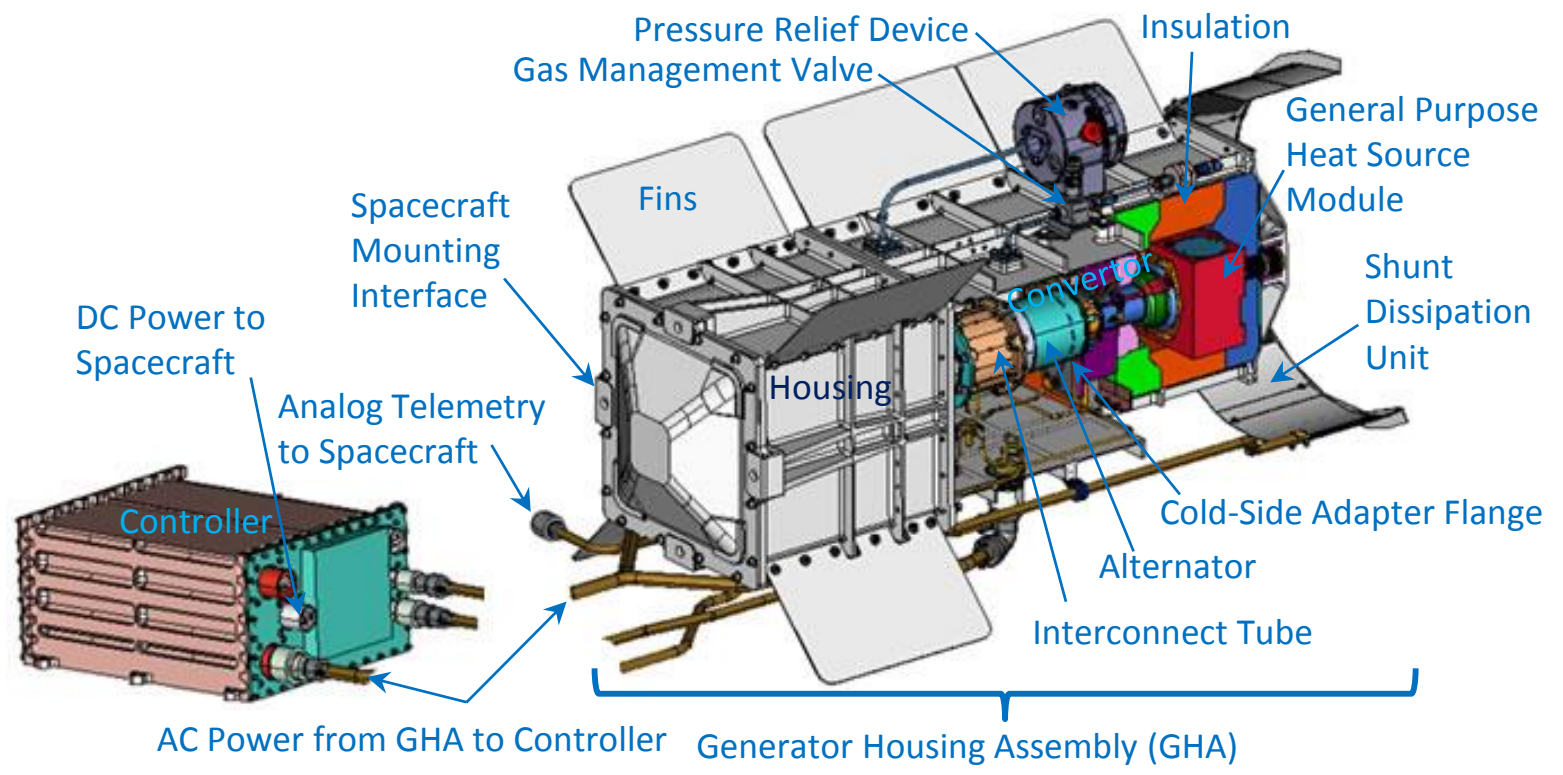

Figure 1. Diagram of the ASRG flight design.

approaches the vacuum of space, improving effectiveness of the insulation that surrounds the heat source. The controller is remotely mounted in a location determined by the mission and connected electrically to the generator housing assembly (GHA) via cables. Connectors on the housing and controller provide electrical interfaces to the alternators, sensors, power input and output, control, and telemetry. The GHA is secured to a spacecraft interface or support via four mounting tabs on one end of the GHA. 
The ASRG EU2 consists of the first pair of Sunpower ASC-E3 convertors (ASC-E3 \#1 and \#2), LM's EDU 4.1 controller (a fourth generation controller), and an aluminum housing. In this paper ASC-E3 \#1 may also be referred to as ASC $\mathrm{A}$, the inboard convertor, and ASC-E3 \#2 as ASC $\mathrm{B}$, the outboard convertor. The integration of these convertors into the GHA is discussed in detail in Ref. 2.

The ASRG EU2 integrated into the test facility is pictured in Fig. 2. There are some obvious differences between the ASRG flight design and the EU2, such as no shunt dissipation unit attached to the end of the EU2 GHA. The major differences between the two units are summarized in Ref. 3 .

\section{B. ASC-E3 \#1 and \#2 operating history}

The convertors in the EU2 were the first ASCE3 pair produced. Sunpower delivered them to

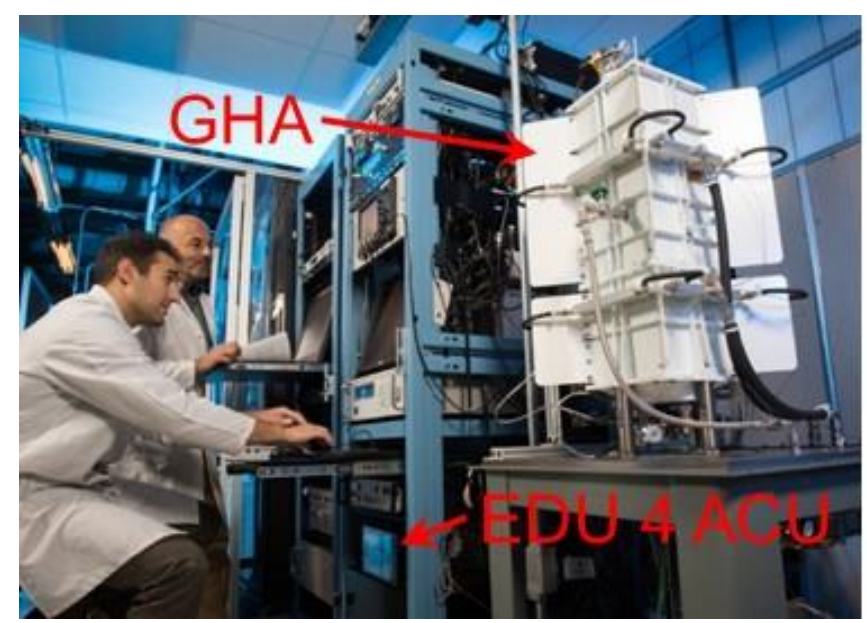

Figure 2. The ASRG EU2 under test in NASA GRC's Stirling Research Laboratory.

GRC in December, 2012. They underwent performance mapping over an extended performance map while mounted in the common test hardware. The common test hardware is the same convertor mounting set-up as was used at Sunpower during production. Figure 3 shows convertor power, hot-end (acceptor) temperature, and cold-end (rejector) temperature over the life of the convertors after delivery to GRC. Performance mapping took place between 0 and 2,355 hours of operation. The convertors were then assembled into a dual-opposed horizontal configuration for testing at LM. They were shipped to LM, tested with the EDU 4 controller, then returned to GRC for integration into the GHA. In September, 2014, the GHA was operated under AC bus control and completed checkout testing. EU2 operation began on September 19, 2014.

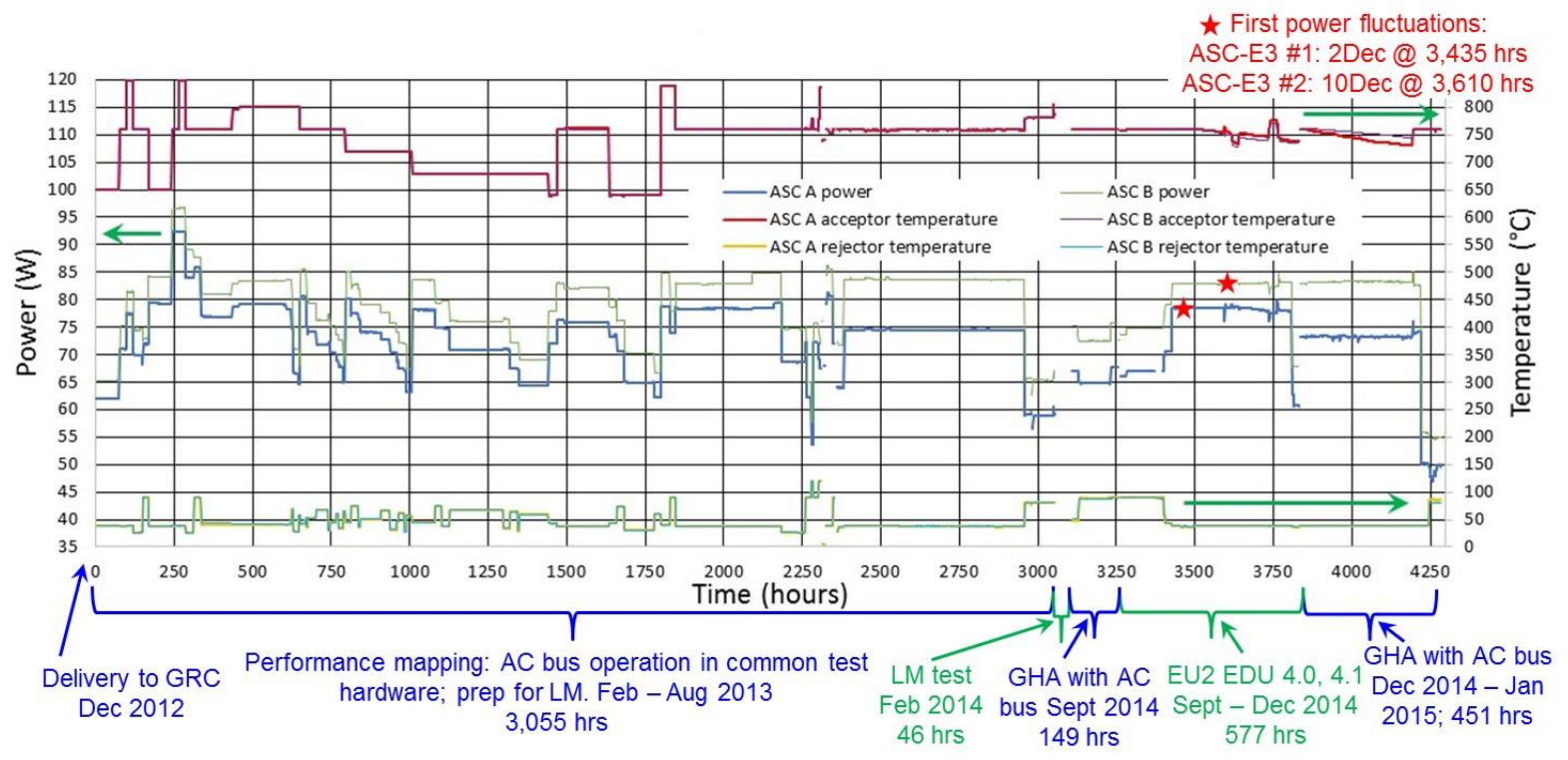

Figure 3. ASC-E3 \#1 and \#2 operating history.

\section{Anomalous Observations}

Test engineers first noticed small power fluctuations on ASC-E3 \#1 as the first indication of a problem with the EU2. After just 179 hours of EU2 generator operation, the first power fluctuation occurred on ASC-E3 \#1 (0.4 W drop) on 2 December 2014. This corresponded to 3,435 total hours of operation for ASC-E3 \#1 since delivery, 328 hours of operation in the GHA under either AC bus or ACU control, and 225 hours of operation under ACU control 
(See Fig. 3). Then 175 hours later the first power fluctuation occurred on ASC-E3 \#2 ( $0.2 \mathrm{~W}$ drop). Figure 4 shows the power fluctuations observed on ASC-E3 \#1 and \#2 during EU2 operation, which appear as short duration decreases in power. Some power fluctuations were as small as 0.2 to $0.4 \mathrm{~W}$ and lasted less than two seconds. Over time they became more frequent and greater in magnitude, with some power fluctuations becoming as large as $9 \mathrm{~W}$ and lasting for many minutes, if not hours.

Although a power fluctuation requirement for the ASC convertor was never finalized, it was generally accepted

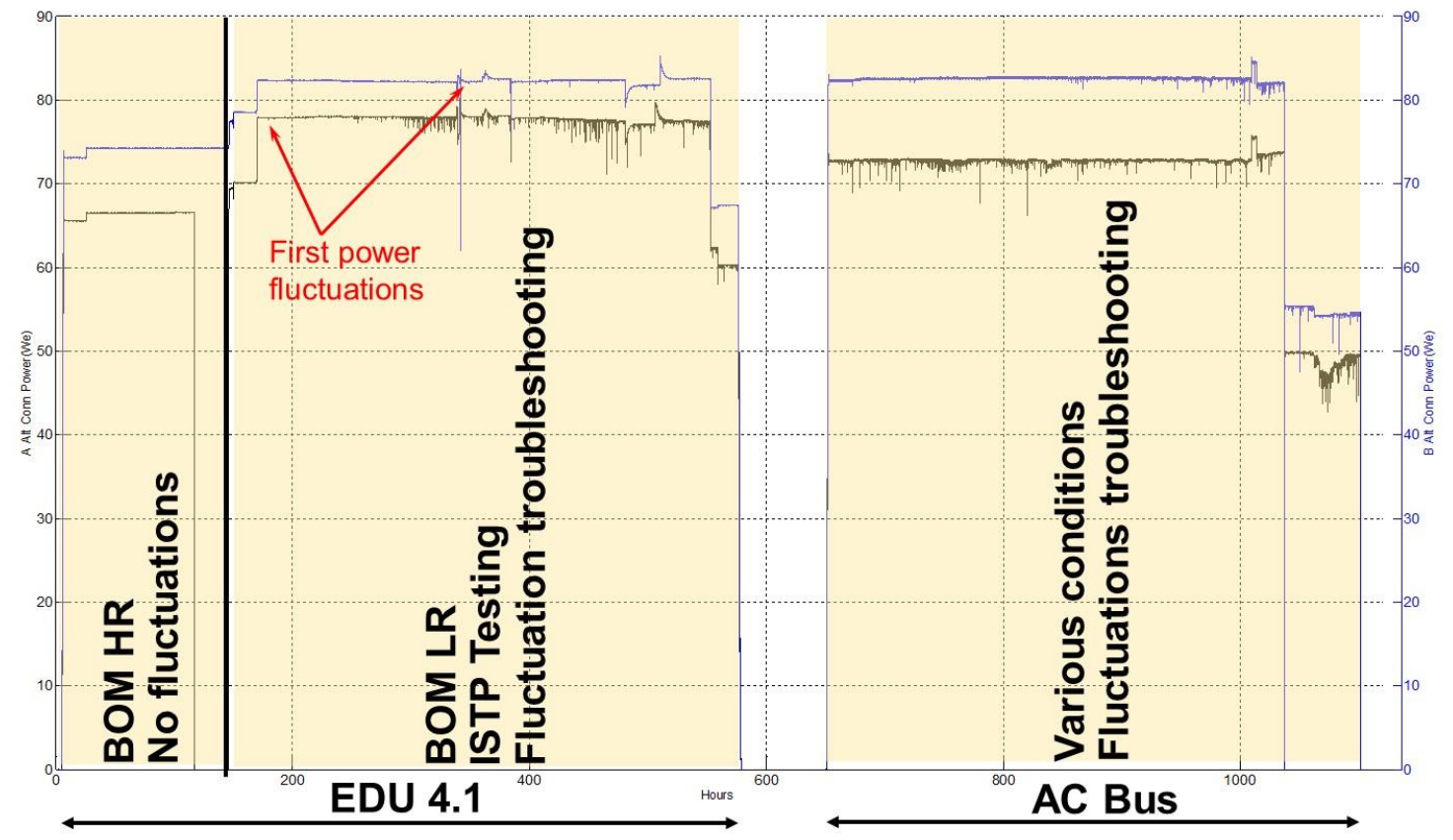

Figure 4. ASC-E3 \#1 and \#2 output power during ASRG EU2 and GHA testing from 25 November 2014 through 1 January 2015 showing power fluctuations.

that power fluctuations from an ASC should certainly be no greater than $1 \mathrm{~W}$, infrequent in rate of occurrence, and for short durations (no more than a few seconds). One could argue that a more stringent requirement is needed, especially if the cause of power fluctuations and the underlying physics is not fully understood.

Fortunately for the investigation, all performance data was recorded during EU2 testing. Parameters were captured at $0.5 \mathrm{~Hz}$, and selected parameters were saved at $7 \mathrm{kHz}$. This data was analyzed and provided additional insights into possible causes for the EU2 anomalies. An example is provided in Fig. 5, which shows $0.5 \mathrm{~Hz}$ data for some power fluctuations that occurred on ASC-E3 \#1 on 14 December 2014. The plot shows 50 minutes of operation. A single power fluctuation of $0.7 \mathrm{~W}$ for less than a 2 second duration occurred at 17.44 hours. The piston amplitude and/or phasing was affected, as indicated by the small increase in transmitted force at the GHA interface and by the increased vibration. While no change in piston amplitude is detected in the $0.5 \mathrm{~Hz}$ data, either due to the slow sample rate or the small magnitude of the change, the $7 \mathrm{kHz}$ data always indicated a change in piston amplitude when a power fluctuation occurred. The vibration signal comes from an accelerometer mounted directly to the ASCE3 \#1 convertor. Interestingly, the increased vibration level persists for a full minute after the power fluctuation.

The next power fluctuation started at 17.52 hours and persisted for at least 0.25 hours ( 15 minutes). The power initially dropped by $6.62 \mathrm{~W}$, then slowly recovered, with fluctuations in power during that process. This time, the piston amplitude clearly dropped (by $0.019 \mathrm{~mm}$ ), then recovered. Because the transmitted force and vibration levels remain high even when piston amplitude returns to near nominal values, this suggests that the relative phasing between ASC-E3 \#1 and \#2 is increased.

Another power fluctuation occurred at 17.82 hours, and so forth. The examples shown in Fig. 5 illustrate typical behavior of power fluctuations. In all cases a power fluctuation results in a decrease, not increase in power.

While power fluctuations were the first anomalous behavior seen with the EU2, a total of six anomalous observations were identified and were included in the scope of the investigation. It wasn't known initially whether all six observations were related or had the same root cause, and the investigation did not assume such. 
The second observation was an audible noise emanating from the Generator Housing Assembly (GHA). This buzzing sound came and went, and often occurred when changing the convertor operating point.

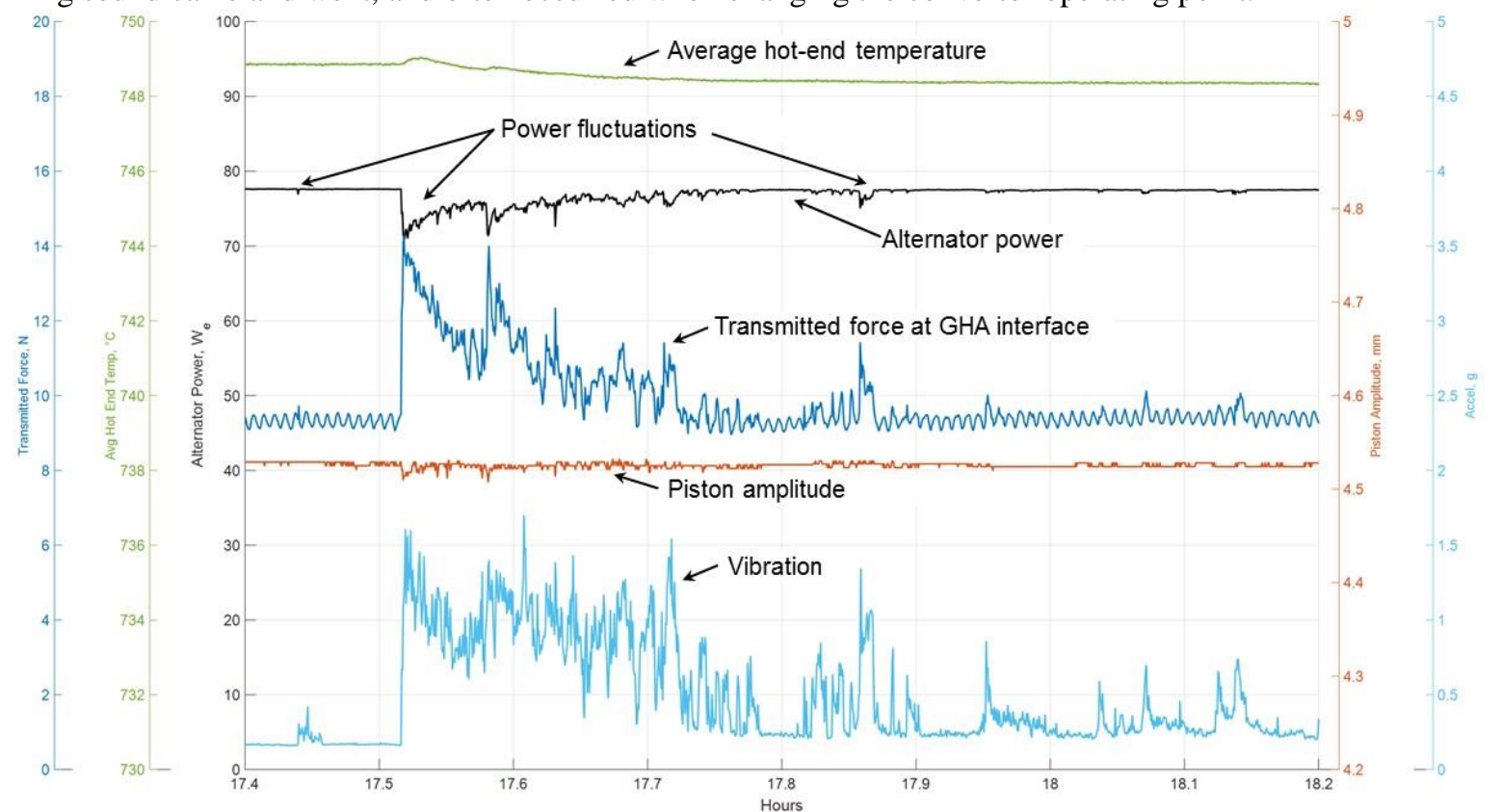

Figure 5. Example of power fluctuations that occurred on ASC-E3 \#1 on 14 December 2014.

The third observation was increased accelerometer readings from the GHA, as discussed previously.

The forth observation was a slow downward drift in hot-end temperature and upward piston amplitude over many hours. The drift began about when the EU2 began operation under fixed heat input at 3,495 hours of ASC operation. Previously the hot-end temperature was fixed, and the test system adjusted heat input to maintain temperature. In Fig. 6, the downward drift in hot-end temperature and upward drift in piston amplitude is clearly seen, superimposed on step changes in hot-end temperature and amplitude when the operating point was adjusted. This drift occurred under both ACU control and AC bus control, which began at 3,833 hours. The ASRG was designed to maintain hot-end temperature and piston amplitude open loop by controlling the ASC voltage setpoint, and this amount of drift was abnormal. This drift can also be seen in figures published previously. The downward drift in hot-end temperature is apparent in Figs. 7 and 8 in Ref. 2 and the upward drift in piston amplitude is seen in Fig. 8 in Ref. 2.

The fifth observation was an increase in the current required to move the pistons in the convertors. The ASC start-up procedure includes applying a DC current to the alternator to move the piston to a certain position. Beginning with the restart under AC bus control (at 3,833 hours in Fig. 3), the current to move ASC-E3 \#1's piston was as much as five times the nominal value. The current to move ASCE3 \#2's piston was abnormally high as well.

The sixth observation was low electrical resistance, about $440 \Omega$, between ASC-E3 \#1 alternator and structure, which was found after

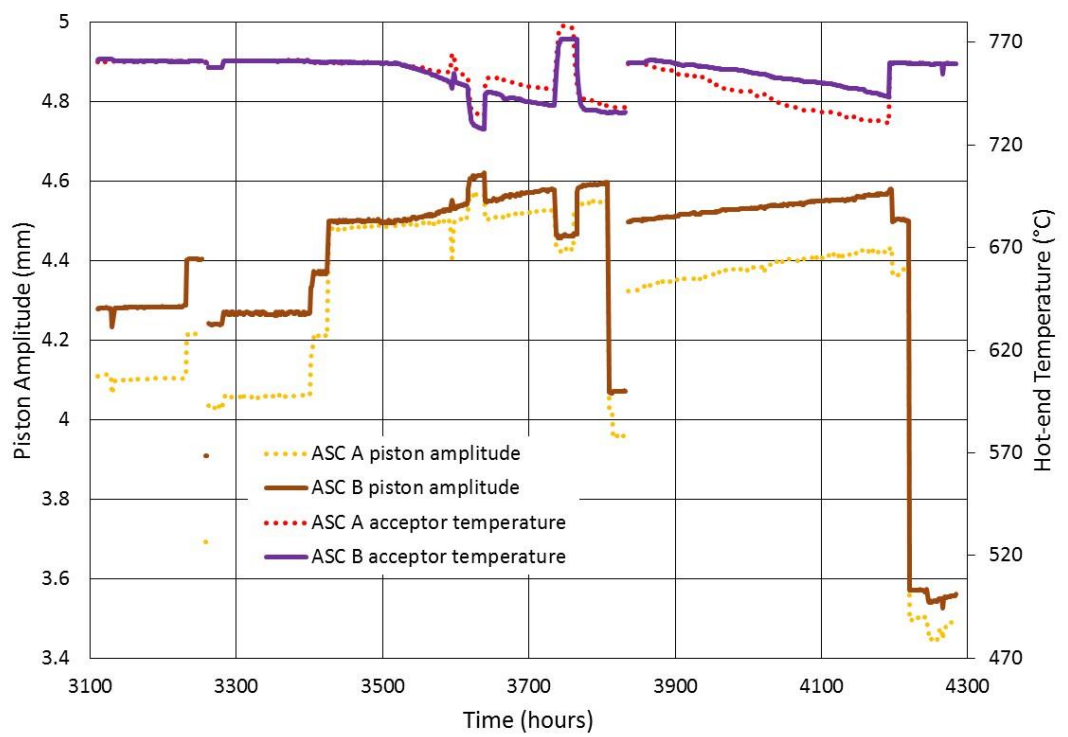

Figure 6. Slow drift in hot-end temperature and piston amplitude during EU2 operation.

American Institute of Aeronautics and Astronautics 
the EU2 was shut down in January, 2015. The alternator leads and structure should be electrically isolated, although the partial short did not affect EU2 performance or any of the electrical measurements by the data system.

After the EU2 was shut down, an electrical check of the alternators revealed that there was a partial short of about $440 \Omega$ between the ASC-E3 \#1 alternator leads and the generator housing, the sixth and final anomalous observation. The alternator leads should be isolated from structure. Analysis of the electrical circuit as well as confirmatory tests of the ground support equipment with a dummy load in place of the alternator indicated that this partial short would not be detectable by any of the telemetry, and that it would not adversely affect EU2 performance.

\section{Anomaly Investigation}

The process followed to investigate the EU2 anomalies is shown in Fig. 7. The investigation team started by developing a fishbone diagram, also known as an Ishikawa diagram, to identify possible causes of the anomalous observations. The fishbone diagram was tailored to accommodate the needs of the EU2 anomaly investigation. Rather than use the typical graphical representation of the relation between causal factors and the effect under investigation, a spreadsheet was used, with causal relationships captured using an outline format. The smaller and smaller bones on a graphical fishbone diagram became lower and lower subbullets in the spreadsheet outline. This approach was necessary because of the scope of the problem, which included possible causes in the convertor, controller, housing, and test rack, and because the team was investigating not just one anomalous observation, but six. The spreadsheet format easily handled the more than 300 possible causes that were eventually identified, and it allowed the team to consider all six anomalous observations simultaneously. This approach let the team consider the possibilities that the observations shared a common cause, the observations could be due to separate causes, or some combination. The spreadsheet format was used to track investigation activity associated with each possible cause, what the results of the investigation activity were, and conclusions related to each possible cause being likely,

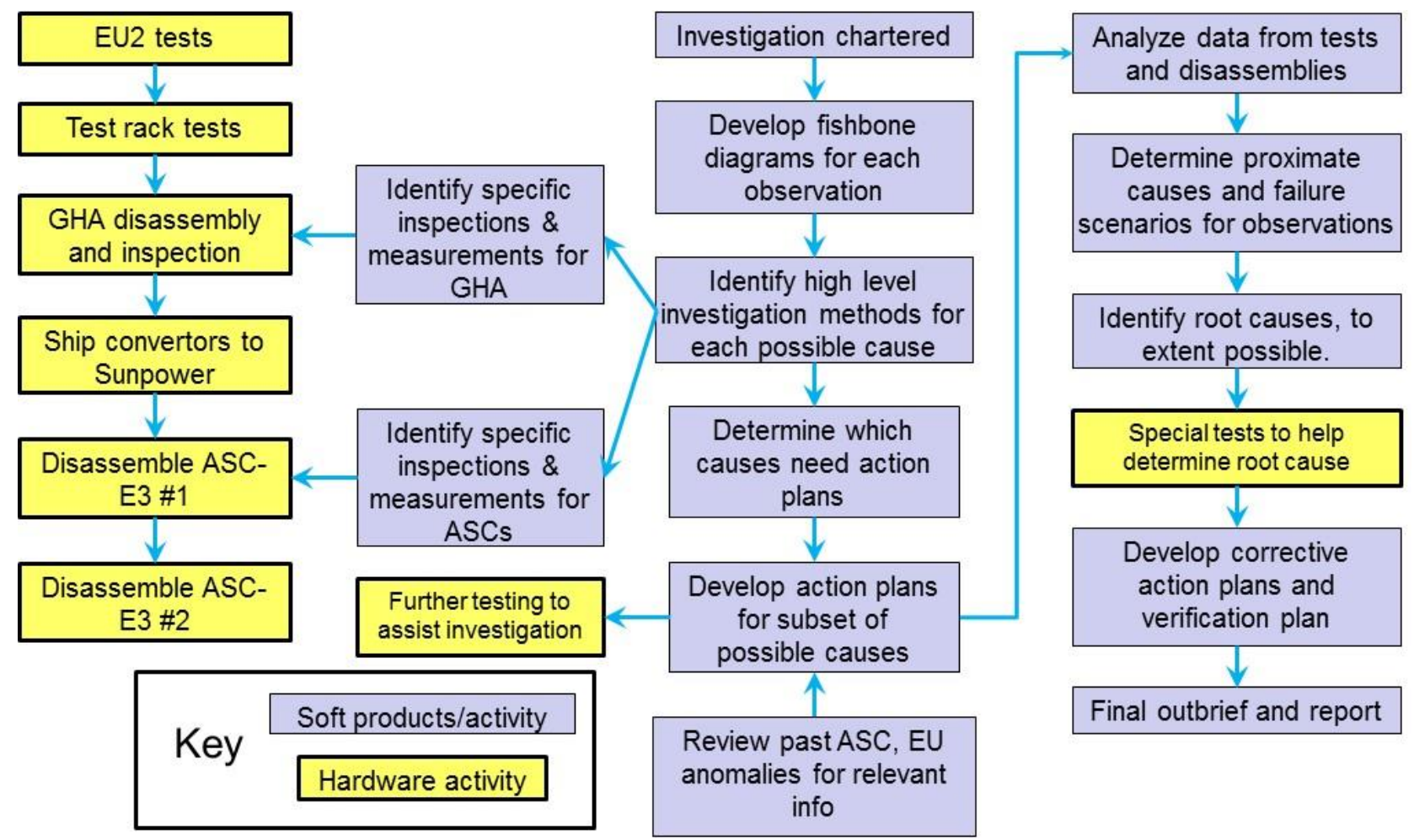

Figure 7. Process followed to investigate EU2 anomalies.

unlikely, or a contributing factor.

Guided by the fishbone diagram, the team developed detailed procedures for disassembling and inspecting the GHA and the two convertors. Great care was taken to maximize information gleaned during disassembly, taking care to minimize the possibility of destroying evidence during the process. 
The team reviewed past ASC and ASRG EU anomalies to glean information that could benefit this investigation. In 2011 the ASRG Project chartered a Red Team investigation into ASC power fluctuations on ASC-E and ASC-E2 convertors. Findings, investigation techniques, and lessons learned from that investigation were leveraged with the EU2 anomaly investigation.

Extensive analysis of available test data from EU2 operation was conducted to evaluate various possible theories. Some finite element analysis and simulation was performed, as well as additional testing at the component and convertor level, to investigate possible causes.

Findings from the GHA and convertor disassembly identified proximate causes of the anomalous observations and eliminated many possible causes.

After the GHA and convertor disassembly was completed and initial analysis performed, the fishbone diagram was reviewed and status of possible causes updated. Causes were assessed as being likely, unlikely, inconclusive, dismissed, or not pursued, based on the new information now available. To guide the process of further narrowing down the root cause, and to determine proximate causes and contributing factors, the team developed failure scenarios based on the possible causes that were assessed as being likely or inconclusive (Table I).

Failure scenarios mapped the evolution of a failure. They started with possible root causes, at least as currently understood, then mapped the evolution of the failure to proximate cause with contributing factors down to the final state of the hardware. They took into account the physics of the system in describing what could have led to what, what had to happen for a particular event to have occurred, and how slow or quickly a particular process might have taken.

At this point in the investigation, the final state of the hardware was known. The team knew from the hardware disassembly what had happened to each component within the convertor. The team also had test data that captured information about the evolution of the failure - the timing and nature of power fluctuations and performance change and degradation. Log books and operational records provided details about how the hardware was operated over its lifetime and known events that occurred. Ideally, one could create a scenario that explained the evolution of a failure from root cause to final state of the hardware that is consistent with all of the data and observations. One must be careful to not conclude that, having created a scenario that is consistent with all data and observations, one has proven that that root cause is in fact the root cause. It is possible that multiple scenarios could be consistent with the data and observations. But if all possible scenarios are considered, and only one is consistent with the data and observations, then that scenario likely describes the failure progression and identifies the root cause.

Table I. Summary of assessment of possible causes in the fishbone diagram.

\begin{tabular}{|l|c|}
\hline Total number of proposed possible causes considered & 356 \\
\hline $\begin{array}{l}\text { Likely } \\
\text { Could be a proximate cause, root cause or contributory factor }\end{array}$ & $\mathbf{3 4}$ \\
\hline $\begin{array}{l}\text { Unlikely } \\
\text { Low but non-zero probability of being a proximate cause, root cause } \\
\text { or contributory factor }\end{array}$ & $\mathbf{3 2}$ \\
\hline $\begin{array}{l}\text { Inconclusive } \\
\text { Some elements of evidence are contradictory or insufficient to } \\
\text { confirm or dismiss }\end{array}$ & \\
\hline $\begin{array}{l}\text { Dismissed } \\
\text { Shown by evidence to be a non-contributory factor }\end{array}$ & $\mathbf{2 1 2}$ \\
\hline $\begin{array}{l}\text { Not Pursued } \\
\text { Absent of an initiating event, they appear to have very low } \\
\text { probability; weren't pursued due to lack of resources }\end{array}$ & $\mathbf{4 7}$ \\
\hline
\end{tabular}

The failure scenarios also served to identify gaps in knowledge or understanding about the physical behavior of the system or progression of failures. This identified follow-on testing or analysis that could be performed to prove, corroborate, substantiate or disprove various theories, since the root cause was not evident yet at that point in the investigation. Failure scenarios were used as part of the Red Team investigation into power fluctuations in 2011, and were found to be an effective tool in that investigation. In the case of the EU2 anomaly investigation, while the proximate cause of power fluctuations and performance change and degradation was clear after GHA and convertor disassembly, the root cause was not. Further investigation would be needed, and the failure scenarios were used to 
guide the process and help identify the next steps in the investigation. The key differences in the failure scenarios were in the initiating event(s) and how the initiating event(s) initially progressed. All failure scenarios were similar in theorizing how the later stages of the failure progressed.

Four failure scenarios were developed and analyzed as part of the root cause investigation. Root cause was believed to be within one of these four failure theories:

1. Collision theory - The failure initiated in the magnet can by collision of the piston assembly (i.e., piston and magnet can) with the displacer and/or the out end of the cylinder assembly. Internal convertor collision events caused magnet damage, magnet debonding, or other changes to magnet can shape, which progresses to final failure.

2. ACU pulse-width modulation (PWM) theory - Some characteristic of LM's ACU PWM current or voltage waveform adversely affected the magnet can, initiating the failure.

3. Magnet can clearance theory - Insufficient running clearance, possibly in combination with imperfect alignment, resulted in magnet rubbing and damage.

4. GHA external forces theory - The external forces applied to the ASCs by the GHA adversely affected internal ASC dimensions sufficiently to initiate the failure, probably through rubbing contact between the magnet can and inner stator and/or outer stator.

\section{Findings from the Investigation}

An extensive amount of data and information was generated over the course of the investigation, of which only a small portion can be included in this paper. Many leads that were pursued became dead ends. This gave the team confidence that the remaining possible causes contained the root cause and contributing factors. This section captures the most significant findings.

\section{A. Findings from GHA disassembly}

The GHA disassembly process was guided by two detailed procedures written specifically for this activity. The procedures included specific inspections and checks along the way, including breakloose torque measurements. Once disassembly was completed, the components were dimensionally inspected using a coordinate measuring machine (CMM). Disassembly of the EU2 GHA showed no changes in the convertor or housing dimensions, within the repeatability of the CMM. Key mating surfaces still had parallelism, perpendicularity, or flatness well within specification.

\section{B. Findings from ASC-E3 \#1 and \#2 disassembly}

After GHA disassembly was completed, the convertors were shipped to Sunpower, the convertor manufacturer, for disassembly and inspection. The disassembly sequence was chosen to carefully and systematically investigate the possible causes and preserve related evidence, identify any possible causes not predicted by the investigation team's initial assessment and ensure as much as possible that no findings would be obscured or lost as a result of these activities. The systematic, phased approach agreed upon for disassembly of the convertors was formally captured as a routing checklist supplemented by detailed procedures for specific steps in the process. The convertor disassembly sequence included pauses to provide for reporting of findings to the team, and assessment of those findings by the team to determine any necessary additions or changes to the planned activities.

ASC-E3 \#1 was disassembled and inspected first because it had experienced much larger power fluctuations, and presumably would have the more obvious evidence. Key findings from ASC-E3 \#1 disassembly are summarized here.

- There was a significant amount of debris found at various locations throughout convertor. The composition was analyzed and determined to be from the permanent magnets, the titanium magnet can, and the alternator laminations.

- Rubs were found on the magnets; significant damage to in-end magnets and magnet can on one side.

- There were dark marks on magnet can beams, determined to be from a Sharpie ${ }^{\circledR}$ marker put on by Sunpower during production.

- Microscopic inspection of the magnet can beams revealed deformed tooling marks on magnet can beams at the locations of the Sharpie ${ }^{\circledR}$ marks. It was later determined that the deformed tooling marks appeared during production at Sunpower, and with deformation at some locations occurring later. The location of the tooling mark deformation is in line with the location of the retaining ring on cylinder assembly.

- There was an axial crack in magnet can in line with in-end magnet damage. 
- There were out-end magnet damage and cracks in magnet can about $120^{\circ}$ from in-end magnet damage. Rubs were found on the magnet can.

- There was a noticeable rub on piston, on side towards the location of the in-end magnet damage.

- There was a noticeable rub on the displacer, in line with location of magnet damage.

- Not surprisingly, with the extensive damage observed to the magnet can, there were significant changes to magnet can dimensions.

The procedure for disassembling and inspecting ASC-E3 \#2 was modified slightly based on what was learned from ASC-E3 \#1 disassembly, to help answer some questions raised by ASC-E3 \#1 findings. Key findings from ASC-E3 \#2 are as follows:

- There was a significant amount of debris found at various locations throughout convertor of consistent nature as with ASC-E3 \#1

- There were rubs on magnets and damage to in-end magnets on one side and out-end magnets on opposite side of the magnet can.

- There was a circumferential crack on the out-end of the magnet can and a crack in a magnet can beam.

- Rubs were found on the inside diameter and outside diameter of the magnet can.

- There was a noticeable rub on the piston, located in line with location of magnet damage.

- There were significant changes to magnet can dimensions.

- Microscopic inspection of magnet can beams showed no evidence of tooling mark deformation. Photos show slight markings on three beams corresponding with the cylinder assembly.

At this point in the investigation, it was clear that rubbing contact between the magnet can and the inner stator and the outer stator was a proximate cause of the power fluctuations and several of the other anomalous observations being investigated. The internal convertor damage found indicated that significant rubbing had occurred in both convertors.

Comparing the findings from ASC-E3 \#1 and \#2 disassemblies, one is struck by how similar the internal damage is. There are some differences, but these differences can be attributed to slight differences in how each failure progressed, how far each failure progressed, and known differences between the two convertors. Given the similarities in findings as well as similarities in how the failures progressed during EU2 operation, it seems likely that both convertors had the same root cause.

\section{Observations Regarding Root Cause, Proximate Cause, and Contributing Factors}

Based on all available evidence from the investigation, the following summarizes what evidence supports or contradicts each of the four failure theories, and draws conclusions about likely root cause and contributing factors.

\section{A. Collision theory}

The collision theory depends on one or more internal collisions occurring in the convertor as the initiating event. Since the two convertors, ASC-E3 \#1 and \#2 had different histories, the collision theory was analyzed separately for the two convertors. With the Sunpower free-piston design, which has a piston assembly that is not constrained axially by flexures, there are several possible locations for collisions, as illustrated in Fig. 8. They are:

1. Between the displacer dome and the heater head dome.

2. Between the displacer body and the piston nose.

3. Between the magnet can beams and the out end of the cylinder

4. Between the in end of the magnet can and the fasteners on the cylinder clamp ring.

5. Between the ASC Position Sensor (APS) sensor core and the spring stand-off. (The APS sensor core and spring stand-off are not shown in Fig. 8, but their location is indicated by arrows.) 
The geometry of ASC-E3 \#1 and \#2 indicated that collision scenario \#3 would occur before collision scenario \#4, and no evidence of contact at location \#4 was found, so that collision scenario was not considered a possible initiating event.

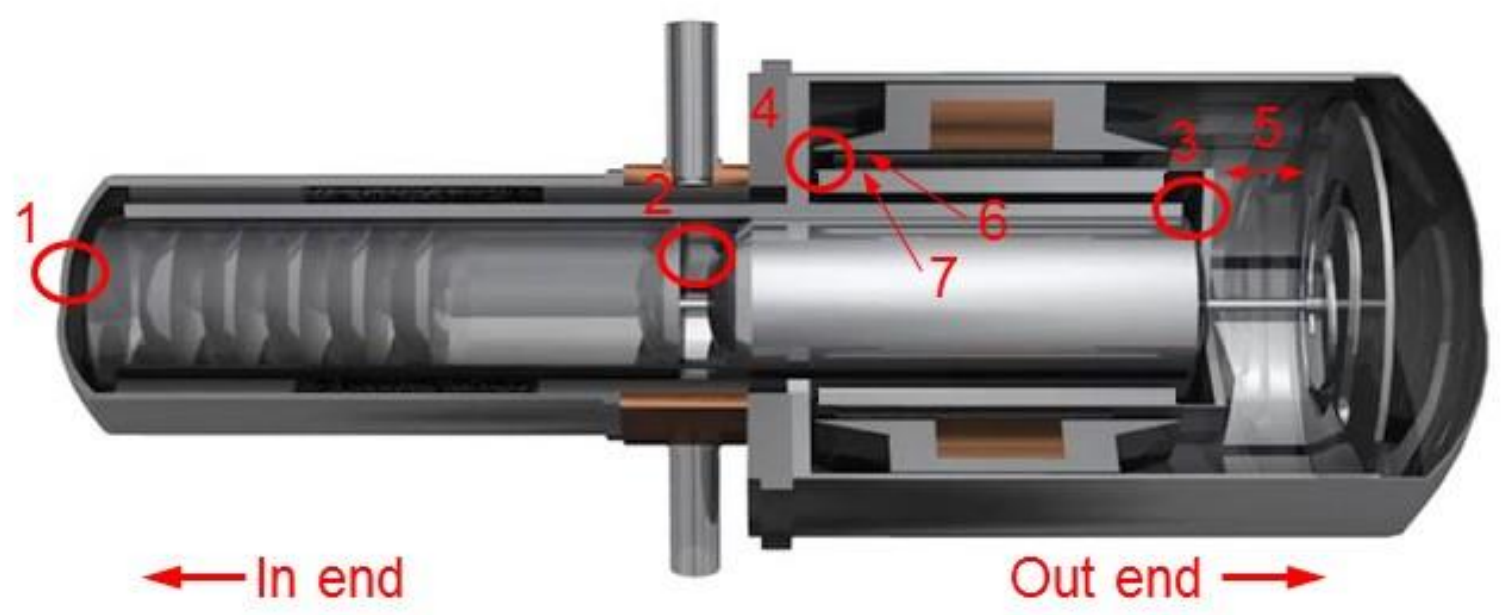

Figure 8. Cross-section of the ASC convertor with possible internal collision locations identified. Numbers described in Sec. V.A.

\section{Collision theory for ASC-E3 \#1:}

There is evidence that collisions occurred with ASC-E3 \#1. During testing at LM on 13 February $2014,{ }^{4}$ ASC-E3 \#1 was operated under EDU 4 control with a high synthetic tuning capacitor value. During shutdown while motoring at $141{ }^{\circ} \mathrm{C}$ hot-end temperature, a controller instability caused the piston amplitude to rise rapidly and caused collisions for about half a second, based on the duration of an audible buzzing sound.

It was also discovered that photographic evidence suggests contact occurred between the magnet can beams and the out end of the cylinder occurred during production at Sunpower in 2012, sufficient to cause tooling mark deformation (location 3 in Fig. 8). This was corroborated by the Sharpie marks found on the magnet can beams and a production log book entry. But a detailed review of available production records and test data and interviews with technicians revealed little detail about the nature of the contact event.

The operating history of the convertor was reviewed, and there is record of mild collisions between displacer body and piston nose occurring during start-up on at least two occasions. Other events were investigated for collisions, but none were positively identified.

A test was conducted with ASC-E2 \#3 and EDU 4.1 to try to recreate the collision event at LM that occurred in 2014. Collisions were recreated, but EMI noise in the piston and displacer position signals made it difficult to determine definitively where the collisions occurred. Further testing at Sunpower with a rapid increase in piston amplitude was able to produce collisions between magnet can beams and the out end of the cylinder.

To try to "connect the dots" between collision events and magnet can damage, drop tests were conducted to simulate collisions between the magnet can beams and the out end of the cylinder. A magnet can - piston assembly was dropped onto a cylinder assembly from varying heights, simulating various impact velocities. The collisions were studied using high-speed video and accelerometers, and the magnet cans and magnet can beams were inspected before and after varying numbers of drops using microscopic imagery, photography, CMM inspection, microfocus computed tomography, and computer-aided tap testing. The collision drop tests were designed to:

- Determine the nature of markings created from collisions at different heights and numbers of collisions,

- Determine the dynamic behavior of the magnet can - piston assembly during collision events,

- Determine what damage occurs to the magnet can at different heights and numbers of collisions. This can include damage to the epoxy bond, the magnets, the magnet can beams, dimensional changes, etc.

Findings from the drop tests showed that because the surface that the magnet can beams contacted on the ASCE3 \#1 cylinder was not flat, the collision would introduce a rocking motion in the magnet can, which could result in contact between the magnets and the outer stator (location 6 in Fig. 8, see also Figs. 9 and 11). If the rocking amplitude is large enough, the magnet can could also contact the inner stator (location 7 in Fig. 8, see also Figs. 9 and 11). The drop tests showed that with sufficiently high impact velocities and number of drops, collisions could 
cause dimensional changes to the magnet can and possibly debond between the magnets and the magnet can. No damage to the magnets was found using microfocus computed tomography.

The assessment of the data is that collisions are likely the cause of ASC-E3 \#1's failure, although the exact mechanism of damage and failure progression is not known, but likely theories have been identified. These theories include localized debond, magnet damage from outer stator contact, and/or reduction in magnet can clearance.

2. Collision theory for ASC-E3 \#2:

There is less evidence of collisions causing damage with ASC-E3 \#2 compared to ASC-E3 \#1. The operational record includes several instances of off-nominal operation. During testing at LM on 13 February 2014, when collisions did occur on ASC-E3 \#1, an extensive review of the available data showed that ASC-E3 \#2's amplitude appeared to decrease, then its controller card browned out. While the data was inconclusive, collisions, especially high impact collisions, are unlikely to have occurred on ASC-E3 \#2 from a brown out during motoring. On another occasion there is record of mild collisions between displacer and piston occurring during start-up. But without a complete record of the operational history, one can't eliminate the possibility that collisions occurred on ASC-E3 \#2.

ASC-E3 \#2 was inspected for evidence of collisions. Microscopic inspection of magnet can beams show no evidence of tooling mark deformation, so if any collisions occurred at this location, the impact velocity was not sufficient to cause tooling mark deformation. Some photos of the magnet can beams show light markings on three of

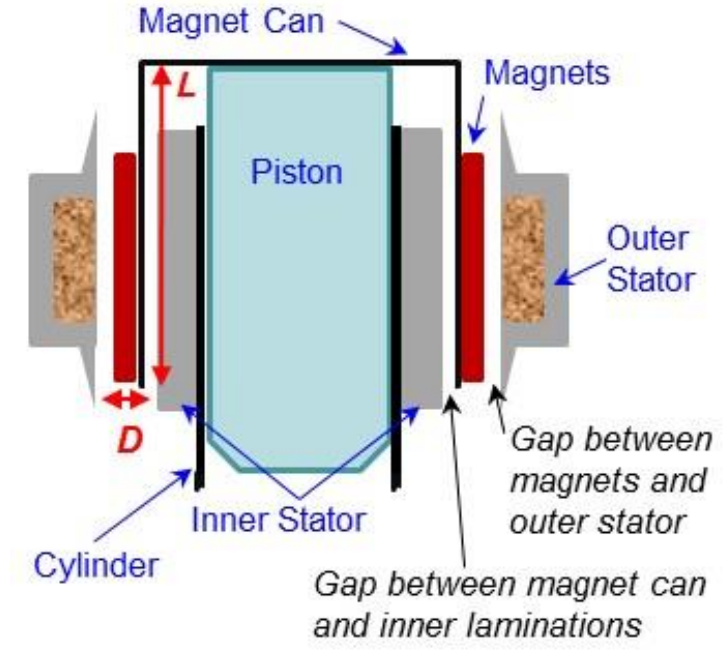

Figure 9. Cross-section of ASC alternator showing location of air gaps. the beams, although what these markings indicate as far as contacts or collisions isn't definitive.

Drop tests were conducted to bound the damage that could have occurred on ASC-E3 \#1 due to collisions, if they did occur. The drop tests showed that the impact velocity and number of impacts was less likely to cause magnet can dimensional changes or debond. The other possibility for damage with ASC-E3 \#1 is that the magnets contacted the outer stator due to rocking. But the ASC-E3 \#2's cylinder has significantly better perpendicularity than ASC-E3 \#1, reducing the amplitude of rocking for a given velocity, if collisions had occurred.

No collision events on ASC-E3 \#2 were confirmed, although the possibility that collisions occurred hasn't been eliminated. Given the similarity between the ASC-E3 \#1 and \#2 failures (timing, characteristics of failure, type of damage), it is likely they had the same root cause. If ASC-E3 \#1 failed because of collisions, it would seem that ASC-E3 \#2 failed due to the same cause.

\section{B. PWM theory}

The PWM theory suggests that some feature in the PWM excitation of the alternator directly or indirectly initiated magnet can damage, which then progressed. The mechanism by which this happens is some adverse interaction between the $40 \mathrm{kHz}$ pulse width modulation control method and the convertor.

The circumstantial evidence points to this as a possibility. After 3,060 hours of operation in convertor-only test hardware and 150 hours in the GHA hardware on AC bus control, ASC-E3 \#1 and \#2 had just 225 hours of operation on an ACU before power fluctuations appeared. And the fact that both convertors exhibited power fluctuations about the same time suggests a common cause.

On the other hand, ASRG EU operated on a similar control algorithm (EDU 1) for 15,000 hours, ${ }^{6}$ but did not show fluctuations until after a long period of operation on AC bus control, at almost 33,000 total hours of operation. (Interestingly, the convertors in the ASRG EU, ASC-E \#2 and \#3, when disassembled after failing, had evidence of magnet can damage.) GRC has operated other ASC convertors with another PWM controller ${ }^{7}$ for over 19,000 hours without incident. And Sunpower has operated several convertors similar in design to the ASC with their PWM controller.

The frequency content of the current, voltage, and accelerometer waveforms were analyzed for frequency content that might be adversely affecting the convertor. With the PWM controller the frequency content of the voltage waveform is significantly different compared to an AC bus controller, but no plausible mechanism by which these differences could adversely affect the convertor was identified. Basic structural dynamics knowledge suggests a mechanical assembly like the magnet can will not respond to high frequencies (20 kHz and above). 
The frequency content of the current waveforms showed almost identical first, second, and third harmonics for both the PWM controller and the AC bus controller. The accelerometer signals showed some additional frequency content between 2 and $3.5 \mathrm{kHz}$ when operating on the ACU, but it seems unlikely there could be enough energy at resonant frequencies to overcome damping and adversely affect the magnet can.

Modal analysis of the magnet can-piston assembly and the outer stator was performed, and these modes were compared to modes found in the current waveform and the accelerometer signal.

Tests were conducted to assess the effect of the PWM on the ASC convertor. The first test involved operating ASC-E2 \#2 on EDU 4.1 for 500 hours. This convertor had been rebuilt to be internally similar to an ASC-E3 convertor. After 300 hours of operation, ASC-E2 \#2 began to show evidence of power fluctuations, but upon disassembly, there was no evidence of damage to the magnets or the magnet can. Inspection did reveal a new rub mark on one end of the piston, which may have been the cause of the power fluctuations.

Following this test, two ASC-E3 convertors (ASC-E3 \#6 and \#8) were operated on EDU 4.1 at a similar operating point to EU2's operating point before power fluctuations started. They were mounted in the common test hardware in a vertical dual opposed configuration, and thus oriented like the convertors in EU2. These convertors have been operated with the EDU 4.1 PWM now for over 1,400 hours, with no evidence of power fluctuations or changes in performance.

Analysis of PWM frequencies and convertor modal frequencies did not identify a likely combination that could result in adverse interactions. Convertor-level testing of ASCs with PWM control did not adversely affect the convertors. So the PWM alone does not appear to have been the cause of the EU2 anomalies.

\section{Magnet can clearance theory}

The magnet can clearance theory postulates that insufficient running clearance, possibly in combination with imperfect alignment of the magnet can within the air gap between the inner stator and the outer stator (Fig. 9), could not accommodate all thermal and dynamic effects encountered during operation. This would result in rubbing contact between the magnets and outer stator and/or between the magnet can and the inner stator, initiating damage and eventual failure.

The 2011 Red Team investigation into power fluctuations had found issues related to magnet can clearance with early ASC designs. There was evidence of insufficient running clearance in the past likely causing power fluctuations. The Red Team recommended changes to outer stator alignment tooling to improve cylinder to outer stator clearance control. ASC-E3 \#1 and \#2 were manufactured with improved tooling that verified outer stator alignment along the full length of the alternator air gap. Later tooling further improved alignment by being able to account for variation within manufacturing tolerances of the parts.

A stacks analysis was performed for ASC-E3 \#1 \& \#2 that made use of as much as-built dimensional inspection data as possible. This analysis showed that the running clearances were adequate for ASC-E3 \#1 and \#2. Further, the convertors had been operated for over 3,400 hours before the power fluctuations started. The convertors had completed performance mapping over the full operating range from minimum qualification to maximum qualification and maximum temperature and in between before being integrated into the GHA. The convertors would have operated with the minimum running clearances during performance mapping, but never exhibited power fluctuations then. When the convertors showed power fluctuations occurred during EU2 testing, the convertors were operating at less extreme temperature conditions with slightly larger running clearances. Therefore, it is unlikely that insufficient running clearance was the root cause of the EU2 anomalies. But it may be a contributing factor, as without the tight clearance, the failures might not have occurred.

\section{GHA external forces theory}

The GHA external forces theory suggests that the forces applied to the ASCs by the GHA adversely affected internal ASC dimensions sufficiently to initiate the failure, probably through rubbing contact between the magnets and outer stator and/or between the magnet can and the inner stator, initiating damage and progressing to eventual failure. Circumstantial evidence suggests this possible cause, as the convertors operated for 3,107 hours with no issues, but after just 328 hours of operation in the GHA, power fluctuations started.

Extensive dimensional inspections from GHA and ASC disassembly found no evidence of distortion or change in geometry, and critical interfaces were well aligned. While GHA material coefficient of thermal expansion (CTE) differences at maximum qualification or maximum temperature conditions would have resulted in large forces at the CSAF, the EU2 was operated only at BOM LR and BOM HR conditions. So the forces applied to the convertors by the GHA were probably not significantly different than forces applied during production, which have not been shown to significantly change internal ASC geometry. Production testing at Sunpower included application of axial forces to the CSAF in both directions followed by inspection of the Xylan running surfaces for evidence of rubbing. 
It is unlikely that the root cause of the EU2 anomalies is due to GHA forces imparted on the convertors. But this theory cannot be completely dismissed. It would require a complete convertor FE model to analyze, and to test this theory, another GHA would need to be fabricated, to more conclusively eliminate GHA external forces as the cause of the EU2 anomalies.

\section{E. Conclusions about the other anomalous observations}

Considering the six anomalous observations under investigation, it now appears that all six are related to a common failure. The magnet can rubbing was the proximate cause of the power fluctuations, the occasional audible noise, and the increased accelerometer readings. The magnet debris between the inner stator and the outer stator in conjunction with the distorted magnet can caused the increase in current required to move the pistons. The slow downward drift in hot-end temperature and upward piston amplitude was due to the loss of magnet material and the decreased moving mass, as confirmed by Maxwell simulations and Matlab/Simulink convertor simulations. The decreased electrical resistance was likely due to a particle embedded in the outer stator that was liberated by magnet can rubbing.

\section{Other Findings from the Investigation}

There were several findings not directly related to the investigation that came out of the EU2 anomaly investigation. These findings are documented here, so that the information is available to inform future generator development. The three findings are heater head crowning, the possible influence of resistance temperature device (RTD) thermal strap on heater head geometry, and Belleville washer relaxation.

\section{A. Heat collector crowning}

During GHA disassembly it was discovered that the ASC heat collectors were slightly crowned, shown exaggerated in Figure 10. The surface around the button in the middle of the heat collector was higher than the surface at the outer diameter by about $0.06 \mathrm{~mm}$ (0.0024 in).

Heat collector crowning did not appear to play a role in the EU2 anomalous observations. Thermal simulations showed that when operating in an argon atmosphere, as was the case with EU2, the gap created by the crowning would not have significantly affected the heat transfer due to the presence of argon in the gap. Further, the change in heat

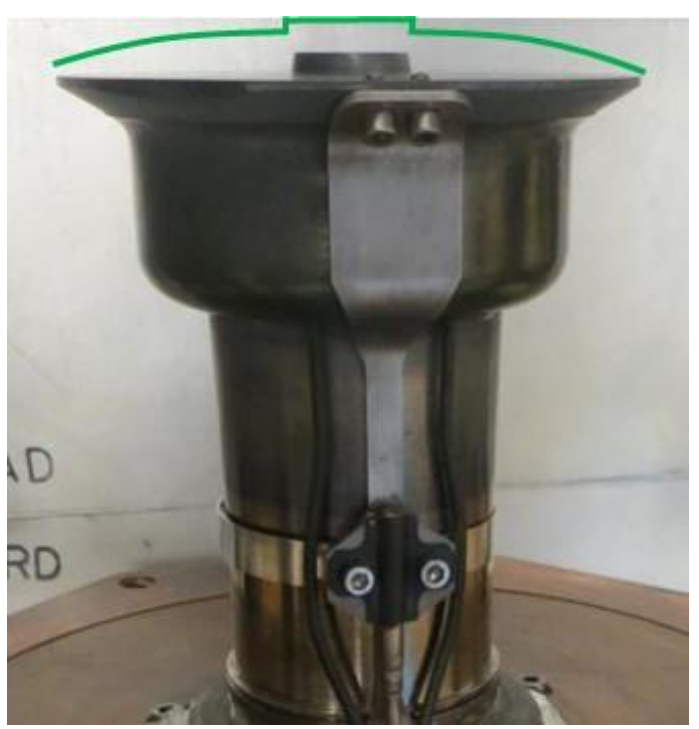

Figure 10. Exaggerated illustration of crowning of ASC-E3 \#1 and \#2 across the heat collector transfer would not have caused the anomalous observations seen in the EU2. However, because $0.06 \mathrm{~mm}$ crowning could adversely affect heat transfer between the heat source and the heat collector in vacuum, the team did investigate further to better understand the cause of the crowning.

Eleven heater heads were inspected from different convertors and from all stages of production. These were all 247LC heater heads with MarM 247 heat collectors. The data show that heat collector crowning was evident on all heater heads, except for the heater heads that had not undergone the high temperature helium leak test. This suggests that crowning begins to occur as soon as the heater head is exposed to high temperatures. The crowning progresses as the convertor goes through production, which includes numerous steps involving operation at the full range of hot-end temperatures. Insufficient data was available to determine whether crowning deformation progresses to a certain point and essentially stops, or continues to deform with continued convertor operation. But the limited data does suggest that crowning does not progress significantly once it reaches about 0.050 to $0.070 \mathrm{~mm}$. Data from the same heat collectors over time would be needed to determine how crowning deformation progresses during operation.

An ASC-E heater head was inspected to see if crowning also occurred on these convertors, which were made of different materials and operated at a lower temperature. The results showed that the ASC-E \#2 heater head was crowned, but the shape of the crowning was different. The Rather than the highest surface occurring at the button in the middle, the highest surface was around half way to the outer diameter. The difference in shape could be due to one or more of the following differences between ASC-E and ASC-E2 and -E3 heat collectors: ASC-E heat 
collectors are made of nickel 201 vs. MarM 247 for ASC-E2 and -E3 heat collectors. The ASC-E heat collector is a one-piece design, vs. two pieces for ASC-E2 and -E3 heat collectors. And ASC-Es are operated at only up to 650 ${ }^{\circ} \mathrm{C}$. Because a preproduction ASC-E heater head was not inspected, it was not confirmed that the crowning deformation occurred during operation and was not already present after heater head machining.

One plausible explanation for heat collector crowning is that it may be caused by creep due to thermal stresses from thermal gradients within the heat collector. Creep occurs at stresses which are less than the high-temperature yield strength of the material. An FEA creep analysis of the ASC-E3 heater head at temperature and pressure did suggest that crowning could occur due to creep.

It is likely that all ASC-E2 and ASC-E3 convertors have crowned heat collectors. The crowning apparently has not adversely affected operation in air or argon environments. However, if any of the ASC-E2 or -E3 assets are operated in vacuum, it may be necessary to take crowning into account when designing the thermal interface. The interface designed by LM between the heat collector and the pressure plate included an approximately $0.13 \mathrm{~mm}$ thick T-gon shim. This shim may not be sufficiently compliant to compensate for the variation in flatness, which could be as much as $0.075 \mathrm{~mm}$, and maintain adequate contact pressure for good heat transfer in vacuum. One possible way to address this issue includes increasing the inside diameter of the T-gon shim to 30 to $35 \mathrm{~mm}$ so that good contact pressure is achieved in the high heat transfer area near the heat collector body.

Future convertor designs should take into consideration the possibility of creep due to thermal stresses in order to prevent crowning or distortion at critical conductively coupled thermal interfaces.

A related effect considered was the possibility that the RTD thermal bridge could affect heater head geometry. The LM ASRG GHA incorporated an RTD mounted to a thermal bridge between the heater collector and the CSAF on the ASC. By using the thermal bridge, the RTD is not exposed to the full hot-end temperature, but it is able to project hot-end temperature for monitoring purposes. ${ }^{5}$ Convertor dimensional inspection uncovered some small dimensional changes that point to the possibility that the RTD thermal bridge could be influencing heater head geometry. However, a detailed review of the data showed that the dimensional biases towards the RTD thermal bridge seen with ASC-E3 \#2 preceded the installation of the RTD thermal bridge, and the changes simply grew over time. There is little evidence showing an effect of the RTD thermal bridge on heater head geometry. That being said, given that there is strong evidence of heater head crowning, and that crowning may be due to thermal creep, it is certainly plausible that nonsymmetrical thermal gradients caused by a thermal bridge or other device could influence localized creep over time, resulting in small asymmetric dimensional changes. Future generator designs should be evaluated for this possibility.

\section{B. Belleville washer relaxation}

The ASRG heat source axial preload system uses Belleville washers or disc springs to apply an axial preload force to maintain contact between the heat source and the ASC heat collector. During GHA disassembly it was observed that the Belleville washer stack had relaxed over the 1,178 hours of GHA operation under both AC bus and ACU control. The preload had dropped from about $325 \mathrm{lbs}$. during operation to about $150 \mathrm{lbs}$, which was still adequate for good heat transfer. The Belleville washer stack spring rates were unchanged, but the stack heights were shorter by between about 0.25 and $0.38 \mathrm{~mm}$.

The Belleville washer materials and operating temperatures were investigated, and it appears that the most likely cause of dimensional change is material creep. The Belleville washer material is full hard 302 stainless steel, with a maximum service temperature of $260^{\circ} \mathrm{C}$ per the manufacturer's data sheet. Thermal analysis by LM showed that the spring cup could reach $250^{\circ} \mathrm{C}$ in the ASRG. The EU2 uses a different preload stud design, but was designed to have a similar thermal resistance as the ASRG. So the EU2 also likely had insufficient temperature margin.

If a future generator design incorporates conductive coupling of the heat source to the convertor with spring preload, the preload mechanism needs to be designed with sufficient margin to prevent significant preload relaxation. Note that the preload relaxation on EU2 occurred over only 1,178 hours of GHA operation without having operated at maximum qualification or maximum temperature conditions, which would have resulted in even higher temperatures at the washers.

\section{Recommendations for Future Convertor and Generator Systems}

While the root cause for the EU2 anomalies was not definitively determined, the corrective actions listed below address weaknesses in the ASRG design and should prevent this failure in the future, regardless of whether the actual cause of the failure was the result of collisions, PWM excitation, or GHA forces. These recommendations may be relevant to varying degrees to other dynamic power conversion systems as well. 


\section{A. Address unintended collisions}

During normal operation, energy flows within the Stirling convertor take thermal energy, convert it to mechanical energy, and then to electrical energy, where it is transferred to a load. If the energy flows are not managed properly, energy can build up inside the convertor, resulting in large piston and displacer amplitudes and internal component collisions. The electrical load needs to be properly matched to the convertor to achieve energy flows within the desired ranges. It is apparent that the attention to training and procedures has not been sufficient to prevent unintended collisions within the ASC from improper loading. Therefore, relying on existing operating procedures, test systems, and training methods to prevent unintended collisions is risky. The investigation team recommended:

1. Further risk mitigation for procedures, test support systems, and training to minimize conditions that result in collisions.

2. The flight Stirling convertor needs to be designed to be tolerant of some level of unintended collisions, or designed in such a way that collisions cannot occur when an incorrect electrical load is applied. The convertor should be designed with inherent robustness to collisions.

\section{B. Make ASC alternator design changes}

The EU2 anomaly investigation team identified two aspects of the ASC alternator design that need to be addressed. The first aspect is associated with the mechanical dynamics of the piston-magnet can assembly. The piston assembly consists of two relatively large masses (piston and magnets) connected by compliant beams and a thin titanium can. Significant inertial, pressure, and electromagnetic forces act on this assembly during nominal operation. During off-nominal operation and unintended collision events, the ASC magnet can may undergo significant dimensional deflection relative to clearances. The magnets on the O.D. of the magnet can rock relative to the piston and can undergo "pogoing" motion relative to the piston, as illustrated in Fig. 11. The ASC magnet can should be designed to acceptable levels of maximum dimensional deflection, even under off-nominal conditions.

The second aspect is associated with the relatively tight alternator air gaps in the ASC alternator. The ASC alternator air gap in combination with the magnet can's high L/D ratio (see Fig. 9) is challenging to manufacture, and creates potential failure modes that reduce robustness to unacceptable levels for a critical component in a nuclear power system.

Further redesign of the ASC alternator tooling and manufacturing processes, to address this aspect is recommended.

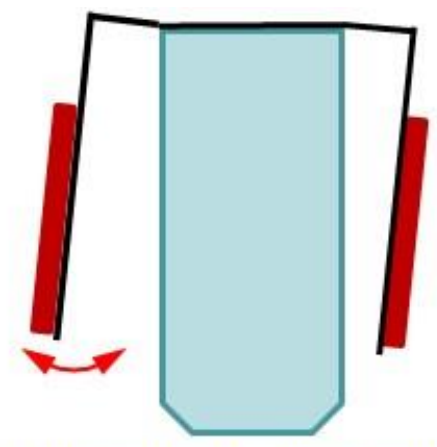

a) Magnet can rocking mode

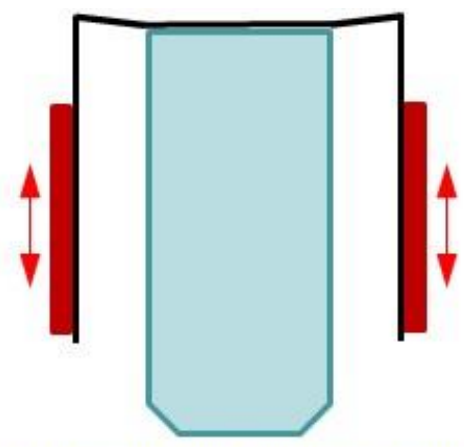

b) Magnet can "pogoing" mode

Figure 11. Illustration of two magnet can modes of oscillation.

\section{Better understand the convertor-controller electrical interface}

The EU2 anomaly investigation team observed that the controller-convertor electrical interface is insufficiently understood and characterized. While the nominal interface parameters have been defined in the ASC and ACU requirements documents, the transient dynamic effects and higher frequency effects haven't been fully explored. The team recommends that the controller-convertor interface be analyzed and characterized over the full frequency spectrum and over all nominal and off-nominal conditions. This will assure that there are no incompatibilities between the convertor and the controller.

\section{Consider off-nominal conditions}


Finally, it is recommended that future flight Stirling convertor design evaluation considers all relevant offnominal conditions and plausible combinations of nominal and off-nominal conditions. Robust system design is more than just designing with margin, but also designing the system to tolerate off-nominal situations that could occur.

\section{Summary}

Using extensive data analysis, modeling, simulation, and testing at the component, subsystem, and system level during an 8-month-long investigation, the EU2 anomaly investigation team narrowed down the causes of the EU2 anomalies. While a definitive root cause was hypothesized but not proven, sufficient clarity in the possible causes was achieved to allow the team to recommend corrective actions to address the possible causes. This effort revealed critical insights into the convertor dynamics and behavior and other findings at the convertor and generator level which should be used to inform the next phase of dynamic radioisotope power system development.

\section{Acknowledgments}

The authors wish to recognize and acknowledge the significant contributions of all who supported the EU2 anomaly investigation. Almost 40 individuals from GRC, Sunpower, and Lockheed Martin played a role in the 8month investigation, with many working long hours to complete this task. Your efforts greatly enhanced our understanding of Stirling systems for the benefit of future dynamic conversion technology development.

This work was funded with the support of the NASA Science Mission Directorate and the Radioisotope Power Systems Program Office. Any opinions, findings, conclusions, or recommendations expressed in this article are those of the authors and do not necessarily reflect the views of NASA.

\section{References}

${ }^{1}$ Oriti, S.M., "Advanced Stirling Radioisotope Generator Engineering Unit 2 (ASRG EU2) Final Assembly," Proceedings of the Nuclear and Emerging Technologies for Space 2015, Albuquerque, N.M., February 23-26, 2015.

${ }^{2}$ Lewandowski, E. J., Oriti, S.M., and Schifer, N.A., "Characterization of the Advanced Stirling Radioisotope Generator EU2," Proceedings of the Thirteenth International Energy Conversion Engineering Conference (IECEC 2015) AIAA, Orlando, FL, 2015. AIAA 2015-3808.

${ }^{3}$ Lewandowski, E. J., Bolotin, G.S., and Oriti, S.M., "Test Program for Stirling Radioisotope Generator Hardware at NASA Glenn Research Center," Proceedings of the Twelfth International Energy Conversion Engineering Conference (IECEC 2014) AIAA, Cleveland, OH, 2014. AIAA 2014-3964.

${ }^{4}$ Chan, T., Wiser, J., Brown, G., Florin, D., and Oriti, S.M., "System-Level Testing of the Advanced Stirling Radioisotope Generator Engineering Hardware," Proceedings of the Twelfth International Energy Conversion Engineering Conference (IECEC 2014) AIAA, Cleveland, OH, 2014. AIAA 2014-3966.

${ }^{5}$ Chan, J., et al., "Design, Qualification and Integration Testing of the High-Temperature Resistance Temperature Device for Stirling Power System," Proceedings of the Thirteenth International Energy Conversion Engineering Conference (IECEC 2015) AIAA, Orlando, FL, 2015. AIAA 2015-3903.

${ }^{6}$ Lewandowski, E. J., "Testing of the Advanced Stirling Radioisotope Generator Engineering Unit at NASA Glenn Research Center," Proceedings of the Tenth International Energy Conversion Engineering Conference (IECEC 2012) AIAA, Atlanta, GA, 2014. AIAA 2012-4253.

${ }^{7}$ Dugala, G.M., et al., "Small Radioisotope Power System Testing at NASA Glenn Research Center," Proceedings of the Eleventh International Energy Conversion Engineering Conference (IECEC 2013) AIAA, San Jose, CA 2013. AIAA $2013-3814$. 